\title{
Dietary patterns and breast cancer risk among women in northern Tanzania: a case-control study
}

\author{
Irmgard Jordan • Antje Hebestreit • \\ Britta Swai • Michael B. Krawinkel
}

Received: 1 September 2011 / Accepted: 4 June 2012/ Published online: 23 June 2012

(C) The Author(s) 2012. This article is published with open access at Springerlink.com

\begin{abstract}
Background Breast cancer is the second most common cancer among women in the Kilimanjaro Region of Tanzania. It was tested within a case-control study in this region whether a specific dietary pattern impacts on the breast cancer risk.

Methods A validated semi-quantitative Food Frequency Questionnaire was used to assess the dietary intake of 115 female breast cancer patients and 230 healthy age-matched women living in the same districts. A logistic regression was performed to estimate breast cancer risk. Dietary patterns were obtained using principal component analysis with Varimax rotation.

Results The adjusted logistic regression estimated an increased risk for a "Fatty Diet", characterized by a higher consumption of milk, vegetable oils and fats, butter, lard and red meat $(\mathrm{OR}=1.42,95 \% \mathrm{CI} 1.08-1.87 ; P=0.01)$, and for a "Fruity Diet", characterized by a higher consumption of fish, mango, papaya, avocado and watery fruits $(\mathrm{OR}=1.61,95 \%$ CI 1.14-2.28; $P=0.01)$. Both diets showed an inverse association with the ratio between polyunsaturated and saturated fatty acids ( $\mathrm{P} / \mathrm{S}$ ratio).
\end{abstract}

I. Jordan $(\varangle) \cdot$ M. B. Krawinkel

Institute of Nutritional Sciences, Justus-Liebig-University

Giessen, Wilhelmstr. 20, 35392 Giessen, Germany

e-mail: Irmgard.Jordan@ernaehrung.uni-giessen.de

\section{A. Hebestreit}

Bremen Institute for Prevention Research and Social Medicine,

Bremen, Germany

B. Swai

Kilimanjaro Christian Medical Center, Moshi, Tanzania
Conclusion A diet characterized by a low $\mathrm{P} / \mathrm{S}$ ratio seems to be more important for the development of breast cancer than total fat intake.

Keywords Breast cancer - Dietary pattern - PUFA . Tanzania

\section{Introduction}

Established factors for breast cancer development are age at menarche, age at menopause, age at first full-term pregnancy, breastfeeding and alcohol consumption at all ages [1-7]. A high percentage of total body fat and tall height at adulthood in postmenopausal women is associated with an increased risk [8-11]. Several studies have looked at possible linkages between single nutrient intake as well as foods or dietary patterns and breast cancer [12-18]. However, there has been limited evidence suggesting that consumption of total dietary fat and special dietary patterns influence breast cancer risk, but no internationally accepted conclusion was reached up to now [7, 19, 20].

In Tanzania, a low-income country where breast cancer is currently the second most common cancer in women, the lifestyle characterized by long-standing lactation or late age at menarche has been associated with a lower breast cancer risk [21]. However, breast cancer occurs, and a pilot casecontrol study in the Kilimanjaro Region of northern Tanzania estimated an increased association between alcohol consumption and breast cancer [22]. A new case-control study looked at dietary patterns rather than single nutrients as nutrients are ingested within diets. A case-control design was chosen because of a lack of demographic data and infrastructural deficits for identification of all women affected to allow for a prospective study approach. 
The study was carried out in collaboration between the Kilimanjaro Christian Medical Centre (KCMC) in Moshi, Tanzania, and the Institute of Nutritional Sciences of the University of Giessen, Germany.

\section{Methods}

Breast cancer patients and controls were recruited in the Kilimanjaro Region between 2004 and 2007. The detailed study methodology has been described previously [21]. In summary, cases were identified using fine needle aspiration cytology (FNAC) confirming primary breast cancer diagnosis. The hospital and visitor-based controls were matched according to age $( \pm 1.5$ years $)$ and lived in the same district for at least 5 years during the past 10 years. The controls were interviewed for their medical history and underwent a physical examination to exclude palpable breast cancer. After informed consent, 115 cases and 230 controls were interviewed by either a trained nurse or a medical doctor in Swahili, based on a standardized questionnaire in English about their socioeconomic situation, current and former lifestyle. At first, the variables were tested for normal distribution, followed by their respective tests for statistically significant differences between cases and controls. The two control groups were analysed for differences in their socioeconomic status using the MannWhitney $U$ test [21].

The present analyses focus on the dietary patterns of both cases and controls using the data of a semi-quantitative food frequency questionnaire (FFQ). The FFQ food list was prepared based on market surveys at different seasons and completed after a pre-test. The relative validity of the FFQ was assessed in 2005 and 2006 based on two nonconsecutive 24-h recalls of 50 randomly selected women with a mean age of 40 years (23-70 years), who did not participate in the case-control study but lived in the same study region. The validation study covered two seasons with different food availability: dry and rainy season. Data collection was done by four trained enumerators. The training included estimation of quantities using common household measurements, for example, cups, spoons, customary packing size, and solid foods in pieces or slices. Foods were prepared according to local standard recipes and weighed using household kitchen scales by the research staff. Countable foods such as onions, eggs or bananas were classified according to their size into small, medium and large. Samples of food pieces were obtained from the local market, and mean weights were taken of each size. The matter of size was intensively discussed in the interviewer trainings to assure a common comprehension. A raw/cooked coefficient was applied when large deviations between cooked and raw foods were expected after preparation, for example, for dried cereals (pasta, rice) and dried legumes. The coefficients were calculated by cooking experiments done by the nutritionist but without calculating any loss of vitamins and minerals. Seasonal food availability on individual level was assessed within the interview, especially for fruits, and a seasonal factor was applied accordingly.

The FFQ data from both, the validation and the casecontrol study, were entered into NutriSurvey ${ }^{\circledR}$, a nutrition software package, which generated tables of the individual food and nutrient intake per day, latter based on food composition tables from Tanzania, Kenya, Senegal, Mali and Germany [23, 24]. All data were converted to gram intake per day for each food item.

For the validation study, the data sets were merged into six food groups to describe individual food intake: (1) cereals: bread, rolls, cereal products, grains, egg-free pasta; (2) vegetables: vegetables, pulses, potatoes, mushrooms; (3) animal products: eggs, dairy and cheese, meat, fish, poultry, sausages and other meat products; (4) beverages: non-alcoholic beverages, coffee, tea, water, alcoholic beverages; (5) fruits; (6) fats: oil, fats, butter. Since the values of most variables were not normally distributed, non-parametric tests were carried out in the subsequent analysis. The studied population had a low educational level, and considering the relative high number of interviewers in relation to the study population, the validation data were tested for interviewer effects before any statistical analysis was performed. The Kruskal-Wallis test chosen to test for homogeneity between the interviewers showed interviewer effects in $100 \%$ of the food groups confirmed by the median one-way test at a level of $83 \%$. Therefore, further analysis was carried out stratified by interviewer. The Wilcoxon signed rank test was used to test the 24-h recall and the FFQ for seasonal variability. It is a non-parametric test equivalent to the paired $t$ test. In addition, the Wilcoxon signed rank test was used to test for differences in the results of the 24-h recall and FFQ. There was no evidence for a seasonal effect in the food groups if the FFQ is used, except for non-alcoholic beverages. Differences in the intake of oils and fats assessed by the validated FFQ and its reference, the 24-h recall, could only be shown by one interviewer. This might be due to low quantification capacities of the studied population especially in this respective food group and especially during the 24-h recall. Furthermore, Spearman correlation was calculated with all interviewers grouped together for comparison with other studies that did not report whether they checked for interviewer bias. The correlation coefficient $\left(r_{\mathrm{s}}\right)$ was highest in the food group "fruits" $\left(r_{\mathrm{s}}=0.39\right.$, $P=0.01)$ followed by "cereals" $\left(r_{\mathrm{s}}=0.38, P=0.01\right)$, "beverages" $\left(r_{\mathrm{s}}=0.33, P=0.01\right)$ and the food groups "animal products" and "vegetables" $\quad\left(r_{\mathrm{s}}=0.27\right.$ and 
$r_{\mathrm{s}}=0.14$, respectively, both values not significant). A negative non-significant correlation coefficient $\left(r_{\mathrm{s}}\right)$ was found in the food group "oils and fats" $\left(r_{\mathrm{s}}=-0.22\right.$, $P=0.13)$. There had been no consistent statistical differences between FFQs and the 24-h recalls, and the correlations were low to modest but comparable to other studies except for oil and fats [25-27]. The negative correlation coefficient for oils and fats might be explained by the difficulties in assessing the oil and fat consumption using the 24-h recall. The reference methods ranged from 7-dayweighed record and 2-day-weighed record to two 7-day food dairies. The high variation in correlation coefficients for the different food groups might be caused by under- or overestimation due to either high fluctuations in food availability or difficulties on the part of the respondents in estimating the quantities of the foods consumed in lowincome countries. However, Parr et al. [28] pointed out that these factors should not be directly linked to the questionnaire design; thus, the tested FFQ was considered a reliable instrument to assess dietary intake in the Kilimanjaro Region.

However, it was recommended paying special attention to the training of interviewers and especially to the assessment of the oil and fat intake. In addition, a calculation for seasonal variability in fruit and vegetable intake was recommended to be used where applicable. The FFQ finally contained in total 65 food items.

From data on individual food intake of the case-control study population, dietary patterns were created using PCA. Although there is a certain disagreement among statistical theorists about it [29-31], PCA was chosen for keeping the results comparable to other studies looking at dietary patterns and disease [20,32-36]. The sampling adequacy of the food group variables for factor analysis was confirmed using the Kaiser-Meyer-Olkin measure. The food items listed in the FFQ were at first merged into 36 food groups for obtaining factors from the PCA defined as dietary patterns. A second PCA was performed based on 34 food groups, excluding alcoholic beverages. Scree plots and parallel analysis were used to quantify the number of factors wanted [31]. Food groups with factor loadings between -0.4 and 0.4 were disregarded for defining the dietary patterns. Differences in body size, metabolic efficiency and physical activity increase the variation in dietary intake, thus requiring energy adjustment. We chose to apply the residual method after performing the PCA to ensure comparability between the dietary patterns $[37,38]$. The final dietary patterns were included in a non-conditional logistic regression model; at first adjusted only for age. Secondly, the dietary patterns were included into the basic model described elsewhere [21]. This model includes the matching variables of age, place of living and the acknowledged predictors in the aetiology of breast cancer from high- income countries. In addition, the body mass index (BMI) of the women at the age of 10 and 20 years as well as current BMI was estimated by each woman herself using a pictogram developed by Stunkard et al. [39] and modified to African settings [21].

If possible, the variables were entered as continuous variables. The variable "age at first full-term pregnancy" was categorized into three groups, "first full-term pregnancy ' $\leq 20$ years', ' $>20$ years', and 'no pregnancy'”.

Descriptive statistics, principal component analysis and logistic regression were performed using the statistical package of SPSS version 18 (SPSS Inc.).

Ethical clearance was obtained from the Research and Ethics Committee of the KCMC, Moshi, Tanzania, and the Ethics Committee of the Faculty of Medicine of the University of Giessen, Germany.

\section{Results}

Selected socioeconomic and reproductive characteristics of the study participants are presented in Table 1 [21]. Mean age of all women was 50 years, and $94 \%$ of them had children. Mean age at menarche was 16 and 21 years at delivery of the first child. Mean lifelong lactation time was 88 months. Breast cancer patients had a significantly lower lifelong lactation time compared to controls. The basic logistic model estimated an increased risk for women with a higher BMI at 20 years, but a reduced risk for women with a high property level and prolonged lactation $\left(\mathrm{OR}_{\mathrm{BMI}} 20\right.$ years $=1.31 ; 95 \% \mathrm{CI}, 1.11-1.55 ; \mathrm{OR}_{\text {high property }}=$ 0.22 ; $95 \% \mathrm{CI}, 0.09-0.55$; and $\mathrm{OR}_{\text {lactation }}=0.99 ; 95 \% \mathrm{CI}$, 0.98-1.00; all $P$ s $<0.01)$.

Median energy consumption in all women was $1,714 \mathrm{kcal}$ per day (min $786 \mathrm{kcal}$; max 3,928 kcal), median protein intake was $47 \mathrm{~g} / \mathrm{day}$ (min $17 \mathrm{~g} / \mathrm{day} ; \max 183 \mathrm{~g} /$ day), median fat intake was $72 \mathrm{~g} /$ day ( $\min 30 \mathrm{~g} /$ day; $\max$ $166 \mathrm{~g} /$ day) and median carbohydrate intake was $188 \mathrm{~g} /$ day ( $\min 85 \mathrm{~g} /$ day-max $537 \mathrm{~g} /$ day). Median percentage of food energy from protein was $12 \%$, from fat $39 \%$ and from carbohydrates $46 \%$. Median alcohol intake from alcoholic drinks was $8.2 \mathrm{~g} /$ day (min, $0 \mathrm{~g} /$ day; $\max , 100 \mathrm{~g} /$ day). Main alcoholic drinks were Mbege (often homemade, locally brewed beer), bottled beer and wine (median intake $57 \mathrm{~g} / \mathrm{day}$, $\min 0 \mathrm{~g} / \mathrm{day} ; \max 298 \mathrm{~g} /$ day and $0 \mathrm{~g} /$ day, $\min 0 \mathrm{~g} /$ day; $\max 77 \mathrm{~g} /$ day respectively).

A PCA was conducted primarily on 36 food groups with Varimax rotation. The Kaiser-Meyer-Olkin measure verified the sampling adequacy for the PCA, $\mathrm{KMO}=0.621$, which is considered as mediocre [40, 41]. Following Kaiser's criterion retaining all components with eigenvalues greater than one, 14 components would have been useful for further analysis. However, the number of food groups with 
Table 1 Selected socioeconomic and reproductive indicators [21]

\begin{tabular}{|c|c|c|c|c|c|}
\hline \multirow[t]{2}{*}{ Variable } & \multicolumn{2}{|l|}{ Cases } & \multicolumn{2}{|l|}{ Controls } & \multirow[t]{2}{*}{$P$ value* } \\
\hline & Median (min-max) & $n$ & Median (min-max) & $n$ & \\
\hline Age (years) & $50(28-85)$ & 115 & $50(26-83)$ & 230 & 0.620 \\
\hline Age at menarche (years) & $16(11-20)$ & 111 & $16(13-20$ & 230 & 0.267 \\
\hline Age at first full-term pregnancy (years) & $20(14-35)$ & 106 & $20(13-41)$ & 217 & 0.571 \\
\hline Number of children ${ }^{a}$ & $5(1-10)$ & 106 & $5(1-9)$ & 217 & 0.219 \\
\hline Lifelong lactation (months) & $90(0-240)$ & 114 & $108(0-240)$ & 230 & 0.045 \\
\hline Schooling (\%) & & & & & 0.119 \\
\hline Less than 3 years & 27 & & 18 & & \\
\hline Finished primary school & 54 & & 59 & & \\
\hline Finished secondary school & 19 & & 23 & & \\
\hline Property level (\%) & & & & & $<0.0001$ \\
\hline Low & 47 & & 18 & & \\
\hline Medium & 45 & & 65 & & \\
\hline High & 8 & & 17 & & \\
\hline Women with children (\%) & 92 & & 94 & & 0.515 \\
\hline
\end{tabular}

* Mann-Whitney $U$ test: differences between cases and controls

a Only parous women

factor loadings $<-0.4$ or $>0.4$ varied between 0 and 11 ; thus, the results were not interpretable. Consequently, it was decided to retain four components as suggested by the scree plot. These four components or dietary patterns describe $29.9 \%$ of the variance in food intake (Table 2). The first pattern is characterized by rice, nuts, eggs, chapati (unleavened East African flat wheat bread), leguminous vegetables, bread, soda and red meat. Since most of these food items are usually purchased, we called it the "Diet of the Rich". Pattern two is characterized by Mchicha, cucumber, okra, onions, carrots, tomatoes, maize, fish and avocado. Mchicha is the Swahili name for amaranth leaf, a traditional food in Tanzania often synonymously used for a dish consisting of amaranth leaves and, for example, onions, tomatoes and/or carrots in various amounts. The pattern was therefore named "Mchicha Diet". The third pattern is characterized by ripe and green banana, sugar, different fruits, tubers, pulses and Mbege. The mountainous area of the Kilimanjaro Region is known for its various banana plants. Therefore, pattern three was called "Banana Diet". Pattern four is characterized by a high consumption of milk, butter, lard, vegetable oils and fats, and a low consumption of sunflower oil and tea. All of the positively loading food items relate to fat, thus we called this pattern "Fatty Diet". With increased affiliation to this Fatty Diet, bread consumption decreased ( $1 \mathrm{st}$ quartile median $=17 \mathrm{~g}$ bread $/ \mathrm{d}$, 4 th quartile median $=9 \mathrm{~g}$ bread $/ \mathrm{d} ; P$ for trend $<0.001)$ and red meat consumption increased (1st quartile median $44 \mathrm{~g}$ / day, 4th quartile median $=52 \mathrm{~g} /$ day; $P$ for trend $=0.09$ ).

The non-conditional multivariate and logistic regression examining the associations between dietary behaviour and breast cancer showed an increased risk association with three out of the four dietary patterns: the Mchicha, Banana and Fatty Diets (Table 3). After including socioeconomic parameters and reproductive variables in the logistic model, the odds ratio (OR) for the Mchicha Diet changed from a significant OR of 1.47 (95\% CI, 1.14-1.88; $P<0.01)$ to a non-significant OR of 1.28 (95\% CI, $0.97-1.7 ; P=0.08)$. The Banana and the Fatty Diets were still associated with an increased breast cancer risk on a significant level. The OR for the Fatty Diet increased to 3.04 (95 \% CI: $1.34-6.91 ; P<0.01)$ among women with the highest consumption (4th quartile). With increased affiliation to the Fatty Diet, total fat intake increased significantly $(P=0.04)$, whereas percentage of energy from fat did not change $(P=0.83)$ and whereas the ratio of polyunsaturated fatty acids to saturated fatty acids (P/S ratio) was inversely associated with breast cancer risk (Fig. 1). However, there was no risk association found between total fat intake (median $72 \mathrm{~g} /$ day) and breast cancer. In addition, there was no change found in risk associations if energy was included into the risk model described above (OR energy $=1.00,95 \%$ CI, 1.00-1.00; $P=0.51)$.

The Banana Diet includes Mbege-a local, often homemade opaque beer from bananas and millet. Acknowledging that alcohol is an accepted risk factor for breast cancer, the factor analysis was repeated excluding the alcoholic beverages from the food group list. In order to get comparable results to the first PCA, we generated six dietary patterns that described $40.3 \%$ of the dietary variance, and four of them were comparable to the Diet of the Rich, 
Table 2 Results of rotated principal component analysis (PCA 1)

\begin{tabular}{|c|c|c|c|c|}
\hline Food item & $\begin{array}{l}\text { Diet of the } \\
\text { Rich }\end{array}$ & $\begin{array}{l}\text { Mchicha } \\
\text { Diet }\end{array}$ & $\begin{array}{l}\text { Banana } \\
\text { Diet }\end{array}$ & $\begin{array}{l}\text { Fatty } \\
\text { Diet }\end{array}$ \\
\hline Variance explained (\%) & 9.1 & 7.9 & 7.6 & 5.3 \\
\hline Rice & 0.618 & 0.205 & -0.143 & -0.170 \\
\hline Nuts & 0.587 & -0.006 & 0.124 & -0.089 \\
\hline Egg & 0.557 & -0.039 & 0.162 & 0.043 \\
\hline Chapati $^{a}$ & 0.556 & 0.062 & 0.055 & 0.009 \\
\hline Leguminous vegetables & 0.537 & -0.093 & 0.006 & -0.026 \\
\hline Bread & 0.503 & 0.362 & -0.220 & -0.190 \\
\hline Soda drinks & 0.471 & 0.108 & -0.028 & -0.155 \\
\hline Red meat & 0.453 & 0.103 & -0.037 & 0.367 \\
\hline Mchicha ${ }^{\mathrm{b}}$ & -0.017 & 0.645 & 0.029 & 0.110 \\
\hline Cucumber and okra & 0.209 & 0.581 & 0.032 & 0.038 \\
\hline Onion & 0.089 & 0.579 & -0.042 & 0.138 \\
\hline Carrots and tomatoes & 0.145 & 0.516 & -0.096 & -0.007 \\
\hline Maize & -0.180 & 0.461 & 0.135 & -0.085 \\
\hline Fish & -0.018 & 0.434 & 0.337 & -0.085 \\
\hline Avocado & -0.016 & 0.413 & 0.347 & 0.067 \\
\hline Banana & 0.145 & 0.030 & 0.667 & 0.073 \\
\hline $\begin{array}{l}\text { Green (cooking) } \\
\text { banana }\end{array}$ & 0.086 & 0.008 & 0.616 & -0.176 \\
\hline Sugar & 0.153 & -0.103 & 0.491 & -0.166 \\
\hline Watery fruits ${ }^{c}$ & 0.085 & 0.189 & 0.478 & -0.218 \\
\hline Starchy tubers & -0.275 & -0.063 & 0.461 & 0.136 \\
\hline Mbege $e^{\mathrm{d}}$ & -0.295 & 0.050 & 0.442 & 0.246 \\
\hline Pulses & -0.070 & 0.281 & 0.415 & 0.134 \\
\hline Sunflower oil & 0.203 & -0.207 & -0.071 & -0.623 \\
\hline Milk & 0.264 & -0.079 & -0.042 & 0.521 \\
\hline Butter and lard & -0.213 & -0.254 & 0.055 & 0.457 \\
\hline $\begin{array}{l}\text { Mixed vegetable fats } \\
\text { and oil }\end{array}$ & 0.263 & 0.191 & -0.115 & 0.454 \\
\hline Tea & 0.055 & 0.013 & 0.366 & -0.410 \\
\hline
\end{tabular}

Food groups with factor loadings $<0.4$ and $>-0.4$ : potatoes, juice, chicken meat, mango, papaya, cabbage (white), mandazi (East African donuts), uji (thin millet or maize-based porridge), coffee, bottled beer and wine. Rotation method Varimax with Kaiser normalization. Rotation converged in 7 iterations

${ }^{\mathrm{a}}$ Unleavened East African flat wheat bread, ${ }^{\mathrm{b}}$ traditional Tanzanian food, synonymously used for a dish of amaranth leaves and, for example, onions, tomatoes and/or carrots in various amounts, ${ }^{\mathrm{c}}$ oranges, watermelon and pineapple, ${ }^{\mathrm{d}}$ often home-made opaque beer from bananas and millet

Mchicha, Banana and Fatty Diets of the first PCA. Table 4 presents the results of the logistic regression including the second set of dietary patterns with the alcoholic beverages included as separated variable. The Mchicha Diet and the Banana Diet were no longer associated with breast cancer risk, but the new Fruity Diet and again a Fatty Diet very similar to the first Fatty Diet were associated with increased risk (OR 1.61, $95 \% \mathrm{CI}, 1.14-2.28 ; P=0 ., 01$ and OR $1.42,95 \%$ CI $1.08-1.87, P=0.01$, respectively). After energy adjustment, the OR for the Fatty Diet declined to 1.43 (95\% CI, 1.04-1.98; $P=0.014$ ), whereas the OR for the Fruity Diet remained at the same level (OR 1.43, $95 \%$ CI, 1.04-1.98; $P=0.03)$.

\section{Discussion}

Several dietary patterns from two principal component analyses with Varimax rotation based on a FFQ were associated with increased breast cancer risk. Two patterns, both called Fatty Diet, are basically characterized by a higher consumption of milk, mixed vegetable oils and fats, butter and lard, but a low consumption of sunflower oil. Both Fatty Diets were associated with an increased risk in different logistical models. A diet rich in fat similar to our Fatty Diets was discussed by Schulz et al. [42] using reduced rank regression, stating that specific fatty acids are less important in populations with a generally higher fat consumption (mean 8.3-10.4 g/MJ). However, this level of dietary fat intake as a proportion of energy intake was comparable to our study population (mean $10.2 \mathrm{~g} / \mathrm{MJ}$ ), but the mean total fat intake in our population was $15 \mathrm{~g}$ per day lower because of the overall lower energy consumption than reported by Schulz et al. [42]. Here, the women's total fat intake was not associated with breast cancer risk (data not shown), although total fat intake increased significantly with increased affiliation to the fatty dietary patterns. Another prospective cohort study found a direct association between dietary fat intake including subtypes and postmenopausal invasive breast cancer [43]. However, they recorded at median $20.3 \%$ energy intake from fat per day in the 1st quintile and $40.1 \%$ energy intake from fat per day in the last quintile. Only the latter energy intake level from dietary fat is comparable to our data. The wide range of fat intake observed in their study population may have resulted in an increased statistical power. This assumption was made by Thiébaut et al. [43] based on the hypotheses from Wynder et al. [44] that a threshold effect may exist for dietary fat, such that it would be difficult to detect an association between fat intake and breast cancer risk in Western populations. They referred to studies about Asian diets in which more people consume diets containing $20 \%$ or less of energy from fat, which have shown significant or borderline significant associations of fat intake and breast cancer risk [43]. The median fat intake as percentage from energy intake in our study population was $39 \%$, which is above this benchmark of $20 \%$ and may explain why no association was found for our population. Regarding the fatty acid composition of the diet, the major PUFA sources reported by Thiébaut et al. were vegetable oils and fats, butter and mayonnaise [43]. Except mayonnaise, these 
Fig. 1 Intake of fat, polyunsaturated and saturated fatty acids per day and its related odds and $\mathrm{P} / \mathrm{S}$ ratios in quartiles of the Fatty Diet

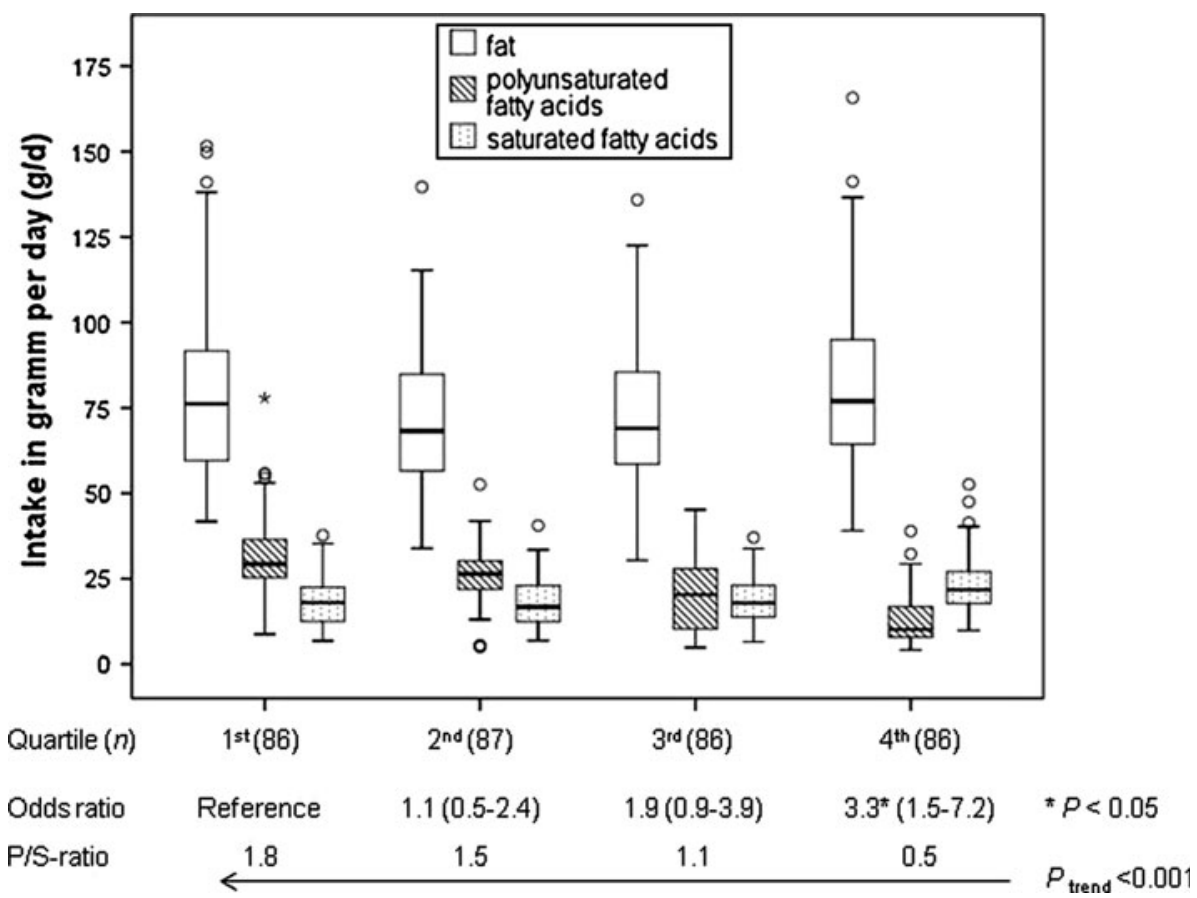

Table 3 Results of the logistic regression: dietary patterns only

\begin{tabular}{|c|c|c|c|c|}
\hline Variable & $P$ value & Odds ratio & $95 \% \mathrm{CI}$ & $n$ \\
\hline \multicolumn{5}{|c|}{ Dietary patterns (PCA 1) } \\
\hline Diet of the Rich & 0.95 & 1.01 & $0.79-1.30$ & 345 \\
\hline Mchicha Diet & 0.00 & 1.47 & $1.14-1.88$ & 345 \\
\hline Banana Diet & 0.00 & 1.94 & $1.43-2.63$ & 345 \\
\hline Fatty Diet & 0.00 & 1.62 & $1.26-2.07$ & 345 \\
\hline
\end{tabular}

Adjusted for age

Constant: $P$ value $<0.01 ;$ OR, 0.56; Cox and Snell $R^{2}=0.13$; Nagerkerke $R^{2}=0.18$

Overall percentage correctly classified, $74 \%$

food items have also been identified by Schulz et al. [42] and in our study as part of dietary patterns rich in fat which have been associated with a higher risk of developing breast cancer. Even if the fatty acid composition of foods varies intrinsically, this composition may be more important than the total fat intake. Our study population showed a negative association of the $\mathrm{P} / \mathrm{S}$ ratio with breast cancer risk (Fig. 1). This negative association was also observed in a case-control study among pre-menopausal women in Singapore, but was attributed to PUFA intake only [12]. However, results from the European Investigation into Cancer and Nutrition (EPIC) study [45] and a case-control study in Connecticut [46] supported the hypothesis of Rose et al. [47] and Key et al. [9] that both saturated and polyunsaturated fatty acids influence inversely the oestrogen metabolism and mammary carcinogenesis. In addition, results from the Shanghai Women's Health study, a prospective cohort study, suggested that the relative amounts of $n-6$ PUFA to marine-derived n-3 PUFAs may be more important for the breast cancer risk than individual amounts of these fatty acids in the diet [48]. They supported the hypothesis that the different PUFA compete as enzyme substrates inside membrane phospholipids [49]: this may also explain the contradictory results of other studies analysing the effect of PUFAs on breast cancer risk [50-52].

Investigators from the Black Women's Health Study, a prospective cohort study, identified a dietary pattern similar to our Fatty Diet called "Western Diet" also based on a PCA with Varimax rotation and factor loadings for dairy products and meat at similar level [53]. However, they associated a lower risk for breast cancer only with another dietary pattern, the "Prudent Diet", characterized with a low consumption of meat and dairy products. Since both the Western and the Prudent Diets were more complex than in our study with each diet having more than 8 foods with factor loadings above 0.4 , it is not known whether the nonrelationship between the Western Diet and breast cancer has been masked by a higher consumption of potentially preventive foods which in turn result in a high $\mathrm{P} / \mathrm{S}$ ratio.

Effect of alcohol on dietary patterns risk association

The reported consumption of the local banana beer, Mbege, increased significantly with increased affiliation to the Fatty Diet $(P$ for trend $<0.001)$. Our data show a higher breast cancer risk for women mainly following the Banana Diet, which was also associated with a high consumption of 
Table 4 Basic breast cancer risk model and dietary patterns

Adjusted for age, place of living, age at menarche, menopausal status, Mbege (often home-made opaque beer), beer and wine

Constant $P$ value $=0.64 ;$ OR, 0.30; Cox and Snell $R^{2}=0.21$; Nagelkerke $R^{2}=0.29$; overall percentage correctly classified $=77 \%$

* Residual method after PCA

\begin{tabular}{|c|c|c|c|c|}
\hline Variable & $P$ value & Odds ratio & $95 \% \mathrm{CI}$ & $n$ \\
\hline \multicolumn{5}{|l|}{ Property level } \\
\hline Low & & & & 87 \\
\hline Medium & 0.00 & 0.37 & $0.20-0.71$ & 198 \\
\hline High & 0.01 & 0.27 & $0.09-0.77$ & 48 \\
\hline \multicolumn{5}{|l|}{ Body mass index $\left(\mathrm{kg} / \mathrm{m}^{2}\right)$} \\
\hline At 20 years & 0.01 & 1.27 & $1.06-1.53$ & 333 \\
\hline At interview & 0.09 & 0.93 & $0.85-1.01$ & 333 \\
\hline \multicolumn{5}{|c|}{ Age at first full-term pregnancy } \\
\hline$\leq 20$ years & & & & 193 \\
\hline$>20$ years & 0.06 & 1.83 & $0.97-3.45$ & 122 \\
\hline No pregnancy & 0.80 & 0.82 & $0.18-3.84$ & 18 \\
\hline Lifelong lactation & 0.02 & 0.99 & $0.98-1.00$ & 333 \\
\hline \multicolumn{5}{|l|}{ Dietary patterns (no alc) } \\
\hline Diet of the Rich (no alc) & 0.17 & 1.28 & $0.90-1.59$ & 333 \\
\hline Energy adjusted* & 0.54 & 1.13 & $0.77-1.66$ & \\
\hline Fruity Diet (no alc) & 0.01 & 1.61 & $1.14-2.28$ & 333 \\
\hline Energy adjusted* & 0.03 & 1.43 & $1.04-1.98$ & \\
\hline Mchicha Diet (no alc) & 0.70 & 1.06 & $0.80-1.40$ & 333 \\
\hline Energy adjusted* & 0.70 & 1.06 & $0.80-1.40$ & \\
\hline Banana Diet (no alc) & 0.12 & 1.32 & $0.93-1.87$ & 333 \\
\hline Energy adjusted* & 0.30 & 1.21 & $0.84-1.75$ & \\
\hline Starchy Diet (no alc) & 0.86 & 1.02 & $0.78-1.34$ & 333 \\
\hline Energy adjusted* & 0.93 & 1.02 & $0.72-1.43$ & \\
\hline Fatty Diet (no alc) & 0.01 & 1.42 & $1.08-1.87$ & 333 \\
\hline Energy adjusted* & 0.01 & 1.43 & $1.08-1.90$ & \\
\hline
\end{tabular}

association. In our study, the alcohol consumption was $8.2 \mathrm{~g} / \mathrm{day}$, which is well below the recommended maximum intake of one drink per day in the European code against cancer [55]. Thus, the alcohol intake in general was probably too low to show an effect.

\section{Fruity Diet}

The Fruity Diet identified in the second PCA-keeping alcoholic beverages separate-was also associated with increased breast cancer risk. This diet is characterized by a high consumption of fish, mango, papaya, avocados and watery fruits like oranges, watermelons and pineapples that are known for their high content of valuable fatty acids, vitamins and micronutrients considered as potentially protective against cancer [56-60]. Nevertheless, several other studies could not show an overall association between fruit and vegetable intake and breast cancer risk [61, 62]. In our study, the Fruity Diet is, like the Fatty Diet, inversely associated with the P/S ratio $\left(P_{\text {trend }}<0.001\right)$, which is caused by a reduced intake of polyunsaturated fatty acids mainly from sunflower oil $\left(P_{\text {trend }}<0.001\right)$, but a stable saturated fatty acid intake $\left(P_{\text {trend }}=0.19\right)$. Thus, we concluded that it is not the fish and fruit intake but the 
Fig. 2 Intake of fat, polyunsaturated and saturated fatty acids per day and its related odds and $\mathrm{P} / \mathrm{S}$ ratios in quartiles of the Fruity Diet

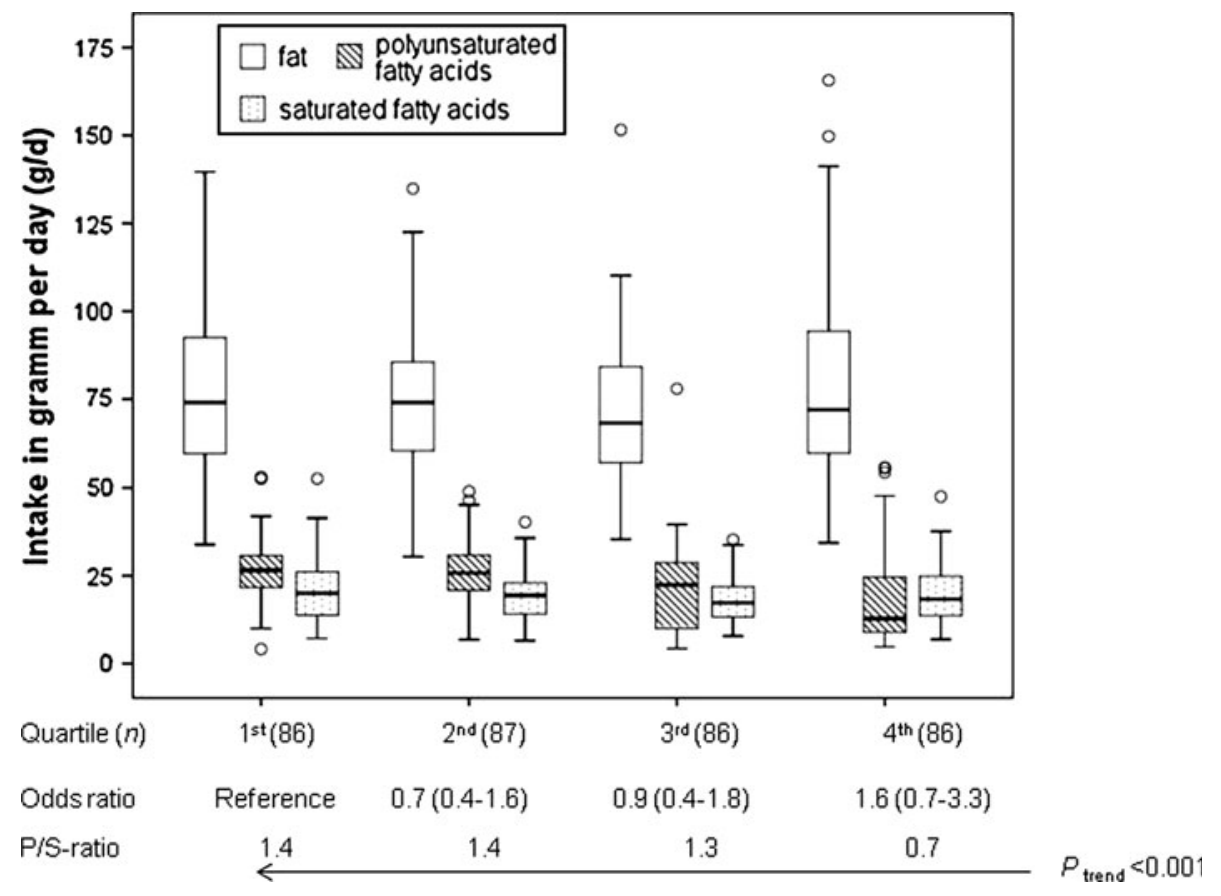

accompanying dietary fat consumption that is associated with breast cancer (Fig. 2).

\section{Property level}

Socioeconomic status (SES) is an internationally acknowledged indicator in epidemiological, economical and sociological studies. However, there is no international consensus on assessing SES, income and household expenditures being the most commonly used measures of SES [63]. In low-income countries like Tanzania, these indicators are difficult to assess. Often, poverty or possession scores are used instead. Studies from low-income countries looking at socioeconomic status and health have shown that a possession score might be even a better indicator of SES, as this score allows greater discrimination in identifying health risks than a poverty index [63]. In this study, a possession score called property, which was used as proxy for SES, showed an inverse association with breast cancer risk. This seems at odds with the statement that higher education and socioeconomic status are associated with an increased risk resulting from the lower number of parities and lactations. However, parity and lactation were correlated with educational level only. Furthermore, educational level was negatively correlated with age indicating a trend towards higher education among the younger women. Education might have an impact on breast cancer risk estimation in the future following the expectation that lactation and parity will reduce over time with increasing educational level. In addition, it is expected that the trend towards higher education and fewer children, thus reduced lifelong lactation, will continue especially with all the efforts towards the MDGs.

We did not find a correlation between lactation, parity and property level. In the context of this study, "low property level" means people can call a bicycle or a radio their own. If they own both, they already belong to the group at "medium property level". Thus, any extra income is used first to improve basic living conditions like nutrition, sanitation and health before it is used for education. Alderman [64] points out that the relationship between possessions to nutrition provides only an indirect answer looking at social transfer programmes in low-income countries aiming at improvement in nutrition and healthcare-seeking behaviour. However, according to Hou et al. [65], it may not be surprising to observe an inverse association between SES and breast cancer risk, as studies have shown that people with low SES develop triple-negative subtypes, which accounts for a substantial proportion of breast cancer in Africa. Nevertheless, they required confirmation by larger population-based studies.

Strengths and limitations

Our data show the impact of reproductive and lifestyle factors on breast cancer aetiology of women in the Kilimanjaro Region. With regard to eating habits and dietary patterns, the diversity of the Kilimanjaro diet is low, and it was less likely to miss important foods on the FFQ food list reducing the estimation bias for dietary behaviour. Due to low education levels and the poor infrastructure, we do not expect socially desirable answers, and participants are less 
likely to be informed about possible dietary impacts on health outcomes. The semi-quantitative FFQ allowed us to identify non-consumers and frequent consumers on the basis of eating habits, nutrient and energy intake in the case and control groups. Also, ready-to-use meals and eating out are uncommon in the Kilimanjaro region, which facilitated the identification of food groups based on single food items and less on complex meals.

The sample is relatively small compared to studies in Westernized countries. The sample size required to achieve a high level of power in a logistic regression depends on the number of predictors and the size of the expected effect. Peduzzi et al. [66] showed that no problems occur by events per variable (EVP) of 10 or more. Also, high regression coefficients and high correlations between the predictors may cause large problems in the estimation process, resulting in very low power even with EVP of 20 or more [67]. Thus, we have tested multicollinearity, which was acceptable in all predictors used. Several studies showed that a sample size like in our studies allows detecting large and medium effects, but might miss small effects. Thus, the results of our study are moderately powered and need to be confirmed by studies with a larger study population.

Before running a PCA, the sampling adequacy was controlled using the KMO measure. The KMO measure, which was 0.62 , is considered as mediocre in our case [68, 69]. A low KMO measure might result in a high unexplained variance. However, in this study, we extracted 6 factors explaining $40.3 \%$ variance, which is a medium result compared to other studies, for example: $\mathrm{Hu}$ et al. $=2$ factors: $20 \%$; Arkkola et al. $=7$ factors: $29.5 \%$; Shi et al. $=4$ factors: $28.5 \%$; Lau et al. $=2$ factors: $17.1 \%$ [69-73]. In addition, Bartlett's test for sphericity was $2,599.25, P<0.001$ indicating that correlations between items were sufficiently large for a PCA.

A major limitation is the PCA method. There have been discussions that the PCA method is less suitable for risk estimations of dietary patterns, because of difficulties to find plausible linkages between dietary patterns and the observed disease [30]. Therefore, it was recommend to use reduced rank regression based on response variables. However, breast cancer develops over a long period of time. Thus, using response variables-such as biochemical parameters-is only possible in prospective studies.

The knowledge about breast cancer and breast selfexamination was very poor in our study population, and facilities for cancer diagnosis and treatment are still rare in countries like Tanzania [74]. In order to avoid a bias, we excluded the family history data for cancer from the analysis.

In the absence of a general health insurance, patients have had to pay for getting access to the health facilities. With the aim to minimize confounding errors due to different livelihood systems between cases and controls, we decided to select the controls also from within the hospital setting. But thereby, other selection biases cannot be excluded.

In conclusion, a dietary pattern rich in fat and characterized by a low $\mathrm{P} / \mathrm{S}$ ratio may be associated with a higher risk of breast cancer. The fatty acid composition is probably more important than total fat intake for the breast cancer risk.

Acknowledgments We thank the participating women of the Kilimanjaro Region and the members of the research team. Greatly appreciated is the input of: Mark Swai for his contribution to the study design and implementation, Joel Julia Mfinanga for conducting the interviews and physical examinations, Johannes Herrmann for statistical guidance and data analysis, and Emma Sykes and Margaret Wightman for the English editing.

Conflict of interest The study was partially funded by Henskes Ltd., Laatzen, Germany, Plural, Sachse and Heinzelmann Ltd., Germany, as well as the German Academic Exchange Service (DAAD). The authors have no conflict of interest.

Open Access This article is distributed under the terms of the Creative Commons Attribution License which permits any use, distribution, and reproduction in any medium, provided the original author(s) and the source are credited.

\section{References}

1. Smith-Warner SA, Spiegelmann D, Yaun SS et al (1998) Alcohol and breast cancer in women. JAMA 279(7):535-540

2. Fioretti F, Tavani A, Bosetti C et al (1999) Risk factors for breast cancer in nulliparous women. Br J Cancer 79(11/12):1923-1928

3. Anonymous (2001) Familial breast cancer: collaborative reanalysis of individual data from 52 epidemiological studies including 58,209 women with breast cancer and 101,986 women without the disease. Lancet 358:1389-1399

4. Beral V et al (2002) Alcohol, tobacco and breast cancer: collaborative reanalysis of individual data from 53 epidemiological studies, including 58515 women with breast cancer and 95067 women without the disease. BJ Cancer 87(11):1234-1245

5. Bofetta P, Hashibe M (2006) Alcohol and cancer. Lancet Oncol 7:149-156

6. Evans DGR, Howell A (2007) Breast Cancer risk-assessment models. Breast Cancer Res 9(5):213

7. World Cancer Research Fund, American Insitute for Cancer Research (2007) Food, nutrition, physical activity, and the prevention of cancer: a global perspective. AICR, Washington DC

8. van den Brandt PA, Spiegelmann D, Yaun SS et al (2000) Pooled Analysis of prospective cohort studies on height, weight, and breast cancer risk in. Am J Epidemiol 152(6):514-527

9. Key T, Appleby P, Barnes I, Reeves G (2002) Endogenous sex hormones and breast cancer in postmenopausal women: reanalysis of nine prospective studies. J Natl Cancer Inst 94:606-616

10. Key T, Appleby PN, Reeves GK et al (2003) Body mass index, serum sex hormones, and breast cancer risk in postmenopausal women. J Natl Cancer Inst 95(16):1218-1226

11. Ahlgren M, Melbye M, Wohlfahrt J, Thorkild IA, Sørensen MD (2004) Growth patterns and the risk of breast cancer in women. N Engl J Med 351:1619-1626 
12. Lee HP, Gourley L, Duffy SW, Estève J, Lee J, Day NE (1991) Dietary effects on breast cancer risk in Singapore. Lancet 337:1197-1200

13. Hunter DJ, Spiegelmann D, Adami HO et al (1996) Cohort studies of fat intake and the risk of breast cancer: a pooled analysis. N Engl J Med 334:356-361

14. Wakai K, Drupadi SD, Ohno Y et al (2000) Fat intake and breast cancer risk in an area where fat intake is low: a case-control study in Indonesia. Int J Epidemiol 29:20-28

15. Mattisson I, Wirfält E, Andrén C, Gullberg B, Berlund G (2003) Dietary fat intake: food sources and dietary correlates in the Malmö diet and cancer cohort. Public Health Nutr 6(6):559-569

16. Cho E, Spiegelmann D, Hunter DJ et al (2003) Premenopausal fat intake and risk of breast cancer. J Natl Cancer Inst 95:1079-1085

17. Prentice RL, Thomson CA, Caan B et al (2007) Low-fat dietary pattern and cancer incidence in the women's health initiative dietary modification randomized controlled trial. J Natl Cancer Inst 99(20):1534-1543

18. Engeset D, Dyachenko A, Ciampi A et al (2009) Dietary patterns and risk of cancers of various sites in the Norwegian European Prospective Investigation into Cancer and Nutrition cohort: the Norwegian women and cancer study. Eur J Cancer Prev 18:69-75

19. Bosetti C, Pelucchi C, La Vecchia C (2009) Diet and cancer in Mediterranean countries: carbohydrates and fats. Public Health Nutr 12(9):1595-1600

20. Brennan SF, Cantwell MM, Cardwell CR et al (2010) Dietary patterns and breast cancer risk: a systematic review and metaanalysis. Am J Clin Nutr 91:1294-1302

21. Jordan I, Hebestreit A, Swai B, Krawinkel MB (2010) Breast cancer risk among women with long-standing lactation and reproductive parameters at low risk level: a case-control study in Northern Tanzania. Breast Cancer Res Treat Published online 20 Nov 2010. doi:10.1007/s10549-010-1255-7

22. Hebestreit A (2004) Brustkrebs und Ernährung. InauguralDissertation zur Erlangung des Grades eines Doktor oec.troph. im Fachbereich Agrarwissenschaften, Ökotrophologie, Umweltmanagement der Justus-Liebig Universität Gießen http://geb.unigiessen.de/geb/volltexte/2004/1544/pdf/HebestreitAntje-2004-0517.pdf. Latest access 12 Jan 2011

23. Landig J, Erhardt JG, Bode JC, Bode C (1998) Validation and comparison of two computerized methods of obtaining a diet history. Clin Nutr 17(3):113-117

24. Erhardt J (2010) http://www.nutrisurvey.de/. Latest access 14 Jan 2011

25. Chen Y, Ahsan H, Parvez F et al (2004) Validity of a foodfrequency questionnaire for a large prospective cohort study in Bangladesh. Br J Nutr 92(05):851

26. MacIntyre U, Venter C, Vorster H (2001) A culture-sensitive quantitative food frequency questionnaire used in an African population: 2. Relative validation by 7-day weighed records and biomarkers. PHN, 4(01). Available at: http://www.journals. cambridge.org/abstract_S136898000100009X. Latest access 8 May 2011

27. Torheim LE, Barikmo I, Hatløy A et al (2001) Validation of a quantitative food-frequency questionnaire for use in Western Mali. PHN 4(06). Available at: http://www.journals.cambridge. org/abstract_S1368980001001161. Latest access 8 May 2011

28. Parr CL, Barikmo I, Torheim LE et al (2002) Validation of the second version of a quantitative food-frequency questionnaire for use in Western Mali. Public Health Nutr 5(6):769-781

29. McCann SE, Weiner J, Graham S, Freudenheim JL (2001) Is principal components analysis necessary to characterize dietary behavior in studies of diet and disease? Public Health Nutr 4(4):903-908

30. Hoffmann K, Schulze MB, Schienkiewitz A, Nöthlings U, Boeing $\mathrm{H}$ (2003) Application of a new statistical method to derive dietary patterns in nutritional epidemiology. Am $\mathrm{J}$ Epidemiol 159:935-944

31. Costello AB, Osborne J (2005) Best practices in exploratory factor analysis: four recommendations for getting the most from your analysis. Pract Assess Res Eval, 10(7) http://pareonline. net/getvn.asp? $v=10 \& n=7$. Latest access 24 Mar 2011

32. Hu FB, Rimm EB, Stampfer MJ, Ascherio A, Spiegelmann D, Willet WC (2000) Prospective study of major dietary patterns and risk of coronary heart disease in men. Am J Clin Nutr 72:912-921

33. Fung TT, Willet WC, Stampfer MJ, Manson JE, Hu FB (2001) Dietary patterns and the risk of coronary heart disease in women. Arch Intern Med 161:1857-1862

34. Handa K, Keiger N (2002) Diet patterns and the risk of renal cell carcinoma. Public Health Nutr 5:757-767

35. Kim MK, Sasaki S, Otani T, Tsugane S (2004) Prospective of three major dietary patterns and risk of gastric cancer in Japan. Int J Cancer 110:435-442

36. Kim MK, Sasaki S, Otani T, Tsugane S (2005) Dietary patterns and subsequent colorectal cancer risk by subsite: a prospective cohort study. Int J Cancer 115:790-798

37. Willett W (1998) Nutritional epidemiology, 2nd edn. Oxford University Press, New York

38. Northstone K, Ness AR, Emmett PM et al (2008) Adjusting for energy intake in dietary pattern investigations using principal components analysis. Eur J Clin Nutr 62(7):931-938

39. Stunkard A, Sorensen T, Schulsinger F (1983) Use of a Danish adoption register for the study of obesity and thinness. The genetics of neurological and psychiatric disorders. Research publications (Association for Research in Nervous and Mental Disease). Raven Press, New York, pp 115-120

40. Cureton EE, D'Agostino RB (1983) Factor analysis: an applied approach. Lea Lawrence Erlbaum Associates, Publishers, Hillside, pp 389-390

41. Backhaus K (2008) Multivariate Analysemethoden: eine anwendungsorientierte Einführung, 12th edn. Springer, Berlin [u.a.], p 575

42. Schulz M, Hoffmann K, Weikert C, Nöthlings U, Schulze MB, Boing H (2008) Identification of a dietary pattern characterized by high-fat food choices associated with increased risk of breast cancer: the European prospective investigation into cancer and nutrition (EPIC)-Potsdam Study. Br J Nutr 100:942-946

43. Thiébaut ACM, Kipnis V, Chang SC et al (2007) Dietary fat and postmenopausal invasive breast cancer in the National Institutes of Health-AARP diet and health study cohort. J Natl Cancer Inst 99:451-462

44. Wynder EL, Cohen LA, Muscat JE, Winters B, Dwyer JT, Balckburn G (1997) Breast cancer: weighing the evidence for a promoting role of dietary fat. J Natl Cancer Inst 89:766-775

45. Sieri S, Krogh V, Ferrari P et al (2008) Dietary fat and breast cancer risk in the European prospective investigation into cancer and nutrition. Am J Clin Nutr 88:1304-1312

46. Goodstine SL, Zheng T, Holford TR et al (2003) Dietary $(n-3) /$ $(n-6)$ fatty acid ratio: possible relationship to premenopausal but not postmenopausal breast cancer risk in US Women. J Nutr 133:1409-1414

47. Rose DP, Conolly JM (1999) Omega-3 fatty acids as cancer chemopreventive agents. Pharmacol Ther 83:217-244

48. Murff HJ, Shu X-O, Li H et al (2010) Dietary polyunsaturated fatty acids and breast cancer risk in Chinese women: a prospective cohort study. Int J Cancer, first published online: 23 Nov 2010. doi:10.1002/ijc. 25703

49. Bougnoux P, Giradeau B, Couet C (2006) Diet, cancer, and the lipidome. Cancer Epidemiol Biomarkers Prev 15:416-421

50. Holmes MD, Hunter DJ, Colditz GA et al (1999) Association of dietary intake of fat and fatty acids with risk of breast cancer. JAMA 281(10):914-920 
51. Saadatoan-Elahi M, Norat T, Goudable J, Riboli E (2004) Biomarkers of dietary fatty acid intake and the risk of breast cancer: a meta-analysis. Int J Cancer 111(4):584-591

52. MacLean CH, Newberry SJ, Mojica WA et al (2006) Effects of omega-3 fatty acids on cancer risk: a systematic review. JAMA 295(4):403-415

53. Argurs-Collins T, Rosenberg L, Makambi K, Palmer JR, AdamsCampbell L (2009) Dietary patterns and breast cancer risk in women participating in the Black Women's Health Study. Am J Clin Nutr 90:621-628

54. Lajous M, Boutron-Ruault MC, Fabre A, Clavel-Chapelon F, Romieu I (2007) Carbohydrate intake, glycemic index, glycemic load, and risk of postmenopausal breast cancer in a prospective study of French women. Am J Clin Nutr 87:1384-1391

55. Boyle P, Autier P, Bartelink H et al (2003) European code against cancer and scientific justification: third version. Ann Oncol 14:973-1005

56. Longnecker MP, Newcom PA, Mittendorf R et al (1997) Intake of carrots, spinach, and supplements containing vitamin $\mathrm{A}$ in relation to risk of breast cancer. Cancer Epidemiol Biomarkers Prev 6(11):887-892

57. Malin AS, Qi D, Shu XO et al (2003) Intake of fruits, vegetables and selected micronutrients in relation to the risk of breast cancer. In J Cancer 105(3):413-418

58. Zhang CX, Ho SC, Chen YM et al (2009) Greater vegetable and fruit intake is associated with lower risk of breast cancer among Chinese women. Int J Cancer 124(12):2929-2937

59. Kim J, Lim SY, Shin A et al (2009) Fatty fish and fish omega-3 fatty acid intakes decrease the breast cancer risk: a case-control study. BMC Cancer 9:216

60. Bofetta P, Couto E, Wichmann J et al (2010) Fruit and vegetable intake and overall cancer risk in the European prospective investigation into cancer and nutrition (EPIC). J Natl Cancer Inst 102:529-537

61. Smith-Warner SA, Spiegelmann D, Yaun SS et al (2001) Intake of fruits and vegetables and risk of breast cancer: a pooled analysis of cohort studies. JAMA 285(6):769-776

62. van Gils CH, Peeters PH, Bueno-de-Mesquita HB et al (2005) Consumption of vegetables and fruits and risk of breast cancer. JAMA 293(2):183-193

63. Mohsena M, Mascie-Taylor CN, Goto R (2010) Association between socio-economic status and childhood undernutrition in
Bangladesh; a comparison of possession score and poverty index. PHN 13:1498-1504

64. Alderman H (2010) What do we want to know about the relationship of wealth or income to nutrition? PHN 13(10):14851486

65. Hou N, Huo D, Olopade OI (2011) Protective effect of longstanding lactation and reproductive factors: a case-control study in North Tanzania. Breast Cancer Res Treat. Available from: http://www.springerlink.com/index/10.1007/s10549-011-1391-8. Latest access 30 Nov 2011

66. Peduzzi P, Concato J, Kemper E et al (1996) A simulation study of the number of events per variable in logistic regression analysis. J Clin Epidemiol 49(12):1373-1379

67. Courvoisier DS, Combescure C, Agoritsas T et al (2011) Performance of logistic regression modeling: beyond the number of events per variable, the role of data structure. J Clin Epidemiol 64(9):993-1000

68. Kaiser HF (1970) A second generation little jiffy. Psychometrika 35:401-415

69. Field A (2009) Discovering statistics using SPSS: (and sex and drugs and rock " $n$ " roll). SAGE, London

70. Hu FB, Rimm E, Smith-Warner SA et al (1999) Reproducibility and validity of dietary patterns assessed with a food-frequency questionnaire. Am J Clin Nutr 69(2):243-249

71. Arkkola T, Uusitalo U, Kronberg-Kippilä C et al (2007) Seven distinct dietary patterns identified among pregnant Finnish women: associations with nutrient intake and sociodemographic factors. PHN. Available from:http://www.journals.cambridge. org/abstract_S1368980007000420. Latest access 7 April 2011

72. Shi Z, Hu X, Yuan B, Hu G et al (2008) Vegetable-rich food pattern is related to obesity in China. Int $\mathrm{J}$ Obes (Lond) 32(6):975-984

73. Lau C, Glümer C, Toft U et al (2007) Identification and reproducibility of dietary patterns in a Danish cohort: the Inter99 study. BJN [Internet]. 99(05). Available from: http://www. journals.cambridge.org/abstract_S0007114507837494. Latest access 7 April 2011

74. Okobia MN, Bunker CH, Okonofua FE, Osime U (2006) Knowledge, attitude and practice of Nigerian women towards breast cancer: a cross-sectional study. World J Surg Oncol 4:11 